\title{
Atmospheric-Pressure Plasma Jet Processed Pt-Decorated Reduced Graphene Oxides for Counter-Electrodes of Dye-Sensitized Solar Cells
}

\author{
Ting-Hao Wan ${ }^{1}$, Yi-Fan Chiu ${ }^{1}$, Chieh-Wen Chen ${ }^{2}$, Cheng-Che Hsu ${ }^{2}$, I-Chun Cheng ${ }^{3,4}$ and \\ Jian-Zhang Chen ${ }^{1, *}$ \\ 1 Graduate Institute of Applied Mechanics, National Taiwan University, Taipei 10617, Taiwan; \\ r04543066@ntu.edu.tw (T.-H.W.); r03543003@ntu.edu.tw (Y.-F.C.) \\ 2 Department of Chemical Engineering, National Taiwan University, Taipei 10617, Taiwan; \\ r04524040@ntu.edu.tw (C.-W.C.); chsu@ntu.edu.tw (C.-C.H.) \\ 3 Graduate Institute of Photonics and Optoelectronics, National Taiwan University, Taipei 10617, Taiwan; \\ iccheng@ntu.edu.tw \\ 4 Department of Electrical Engineering, National Taiwan University, Taipei 10617, Taiwan \\ * Correspondence: jchen@ntu.edu.tw; Tel.: +886-2-3366-5694
}

Academic Editor: Alessandro Lavacchi

Received: 31 July 2016; Accepted: 10 October 2016; Published: 13 October 2016

\begin{abstract}
Ultrafast atmospheric-pressure plasma jet (APPJ) processed Pt-decorated reduced graphene oxides (rGOs) were used as counter-electrodes in dye-sensitized solar cells (DSSCs). Pastes containing rGO, ethyl cellulose, terpineol, and chloroplatinic acid were screen-printed and sintered by nitrogen dc-pulse APPJs. Pt nanodots were uniformly distributed on the rGO flakes. When using Pt-decorated rGOs as the counter electrodes of DSSCs, the efficiency of the DSSC first increased and then decreased as the APPJ processing time increased. Nitrogen APPJs can effectively remove organic binders and can reduce chloroplatinic acid to $\mathrm{Pt}$, thereby improving the efficiency of DSSCs. However, over-calcination by APPJ can damage the graphenes and degrade the DSSCs. The addition of Pt mainly improves the fill factor, which thereby increases the efficiency of DSSCs. The optimized APPJ processing time was merely $9 \mathrm{~s}$ owing to the vigorous interaction among the rGOs, chloroplatinic acid and nitrogen APPJs.
\end{abstract}

Keywords: atmospheric pressure plasma; dye-sensitized solar cells; graphene; reduced graphene oxide; chloroplatinic acid; platinum; composites

\section{Introduction}

Atmospheric-pressure plasma (APP) is operated at atmospheric pressure without using vacuum pumps and chambers that are costly and require routine maintenance. Recent developments have overcome problems such as high breakdown voltage, continuous arcing, and instability, making APP a promising tool for industrial applications [1,2]. Some typical types of APPs include dielectric barrier discharge (DBD), corona discharge, atmospheric pressure plasma jets (APPJs), and microplasmas. Various plasma excitation techniques can produce APPs with different gas temperatures and charge densities; the synergetic effects of a highly energetic plasma species and temperature can achieve versatile functions in material processing [3-11].

Carbon-based nanostructure materials such as one-dimensional carbon nanotubes and two-dimensional graphenes have attracted much research attention owing to their unique physical and chemical properties [12]. Graphene is a planar honeycomb-like lattice with exceptionally high electron mobility [13]. Atomic doping and surface group attachment can be used to efficiently tailor the properties of graphenes to produce various types of graphene-based derivatives [14-16]. Pt-decorated 
graphene is an interesting graphene-based composite that has high electrochemical reactivity. $\mathrm{Pt}$, as a catalyst, can enhance electrochemical performance; therefore, Pt-decorated graphenes are frequently used in electrochemical sensors [12,17-19] and dye-sensitized solar cells (DSSCs) [20-23]. By combining $\mathrm{Pt}$ and graphenes (or rGOs) to form a composite, the required amount of $\mathrm{Pt}$ can be reduced while maintaining catalytic functionality.

Various fabrication processes have been used for producing Pt-decorated graphenes. For example, Chartarrayawadee et al. applied electrophoretic deposition to deposit Pt/graphene nanocomposites [17]; negatively charged graphenes and Pt nanoparticles are driven by the electric field and deposited on the substrates. Kaniyoor et al. used a chemical reduction method to disperse Pt nanoparticles onto graphenes [12]. Dao et al. drop-casted chloroplatinic acid solution onto previously calcined graphene oxides, heated the sample at $70{ }^{\circ} \mathrm{C}$ for $10 \mathrm{~min}$ to dry the solvent, and then reduced the sample using Ar APP for 15 min [20]. In this study, we mixed chloroplatinic acid into pastes containing rGOs. After screen-printing the pastes, a nitrogen dc-pulse APPJ was used to sinter the printed materials. The optimized APPJ sintering time was merely $9 \mathrm{~s}$, thus affording ultrafast processing capability with low energy consumption [6,24]. DSSCs with APPJ-processed Pt-decorated rGO counter electrodes were also implemented successfully.

\section{Materials and Methods}

\subsection{Preparation of Graphene/Pt Pastes}

An amount of $0.1 \mathrm{~g}$ of rGOs (purity: $99 \%$, thickness: $<5 \mathrm{~nm}$, size: $0.1-5 \mu \mathrm{m}$, Golden Innovation Business Co., Ltd., New Taipei City, Taiwan) was mixed with $3.245 \mathrm{~g}$ of terpineol (anhydrous, \#86480, Fluka, St. Louis, MO, USA), $1.75 \mathrm{~g}$ of $10 \mathrm{wt} \%$ ethyl cellulose ethanolic solution (5-15 mPa.s, \#46070, Fluka), $2.25 \mathrm{~g}$ of $10 \mathrm{wt} \%$ ethyl cellulose ethanolic solution (30-50 mPa.s, \#46080, Fluka), and $1.5 \mathrm{~g}$ of ethanol. The mixture was then stirred by a magnetic stirrer for $24 \mathrm{~h}$ at a rotation speed of $850 \mathrm{rpm}$. Next, a $4 \mathrm{~mL}$ mixture was condensed using a rotovap at $55{ }^{\circ} \mathrm{C}$ for $5 \mathrm{~min}$. A chloroplatinic acid $\left(\mathrm{H}_{2} \mathrm{PtCl}_{6}\right)$ solution was made by adding $0.0258 \mathrm{~g}$ of $\mathrm{H}_{2} \mathrm{PtCl}_{6}$ (purity: $99.95 \%$, UniRegion Biotech, Taipei, Taiwan) into $2 \mathrm{~mL}$ of isopropanol. Four different volumes of chloroplatinic acid solution 25, 50, 75, and $100 \mu \mathrm{L}$ were mixed into the pastes to form graphene/Pt pastes. The mixture containing chloroplatinic acid solution was stirred using a magnetic stirrer for $24 \mathrm{~h}$ before use.

\subsection{Preparation of $\mathrm{TiO}_{2}$ Pastes}

An amount of $1.6 \mathrm{~g}$ of $\mathrm{TiO}_{2}$ nanoparticles (Diameter: $21 \mathrm{~nm}$ ), $6.49 \mathrm{~g}$ of terpineol (anhydrous, \#86480, Fluka), $4.5 \mathrm{~g}$ of $10 \mathrm{wt} \%$ ethyl cellulose ethanolic solution (5-15 mPa.s, \#46070, Fluka), $3.5 \mathrm{~g}$ of $10 \mathrm{wt} \%$ ethyl cellulose ethanolic solution (30-50 mPa.s, \#46080, Fluka), and $8 \mathrm{~mL}$ of ethanol were mixed and stirred by a magnetic stirrer for $24 \mathrm{~h}$ at a rotation speed of $850 \mathrm{rpm}$. The mixture was then condensed using a rotovap at $55^{\circ} \mathrm{C}$ for $30 \mathrm{~min}$. Next, $0.4 \mathrm{~g}$ of the mixture was mixed with $0.5 \mathrm{~g}$ of ethanol and baked in a furnace at $55^{\circ} \mathrm{C}$ to evaporate the solvent to $0.175 \mathrm{~g}$.

\subsection{Operation Parameters of APPJ}

Figure 1 shows a schematic of the APPJ apparatus. A quartz tube was installed downstream of the APPJ to prevent the air-quenching effect. The plasma influencing region can therefore be increased. The nitrogen APPJ was operated under a $50 \mathrm{slm}$ nitrogen flow, a $275 \mathrm{~V}$ operation voltage, and a 7/33 $\mu \mathrm{s}$ $\mathrm{ON} / \mathrm{OFF}$ duty cycle. The applied voltage was then raised to $>10 \mathrm{kV}$ with a transformer. The distance between the APPJ nozzle exit and the sample stage was $2 \mathrm{~cm}$, and the gap between the quartz tube and the sample stage was $1 \mathrm{~mm}$. More details have been described elsewhere [3,6-10,24]. The substrate temperature was measured using a K-type thermocouple and recorded with a computer. Figure 2 shows the substrate temperature evolutions under APPJ operation for 5, 9, and $14 \mathrm{~s}$. After the APPJ was ignited, the temperature rapidly increased to $510^{\circ} \mathrm{C}$ and gradually became steady. The temperature rapidly decreased after the APPJ was turned off. 


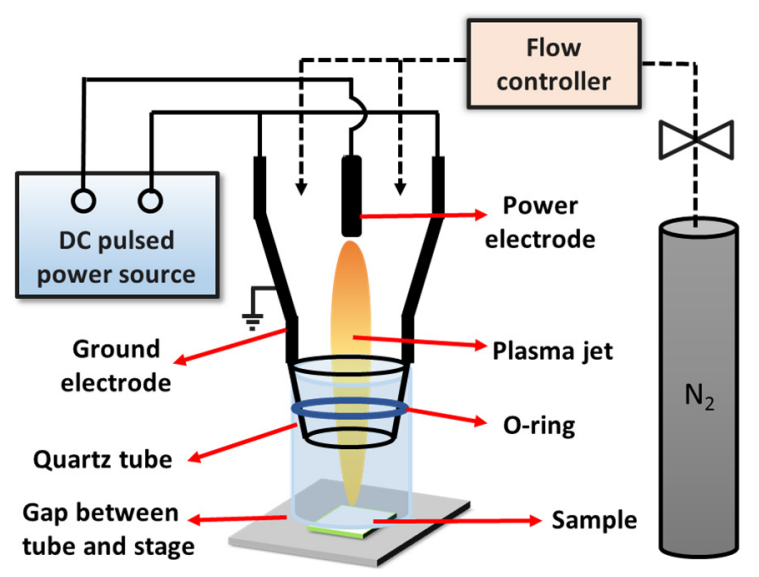

Figure 1. Schematic of the atmospheric-pressure plasma jet (APPJ) setup.

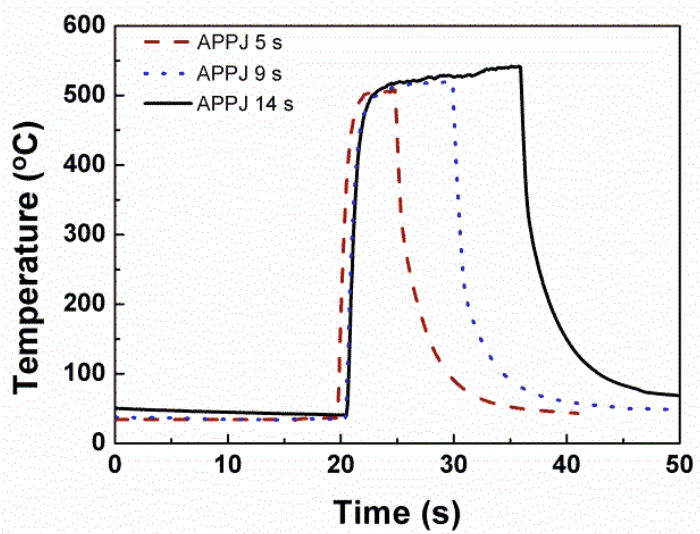

Figure 2. Substrate temperature evolutions under APPJ operation for 5, 9, and $14 \mathrm{~s}$.

\subsection{Assembly of DSSCS}

For fabricating the $\mathrm{TiO}_{2}$ photoanode, $\mathrm{TiO}_{2}$ pastes were screen-printed on fluorine-doped tin oxide (FTO) glass substrates. The printed area is $0.5 \mathrm{~cm} \times 0.5 \mathrm{~cm}$. After printing two consecutive layers, the sample was baked at $100{ }^{\circ} \mathrm{C}$ for $10 \mathrm{~min}$. This printing process was repeated three times. The sample was then calcined at $510^{\circ} \mathrm{C}$ for $10 \mathrm{~min}$. The $\mathrm{TiO}_{2}$ photoanodes was immersed in a solution containing N719 dye for $24 \mathrm{~h}$. The N719 concentration is $0.3 \mathrm{mM}$, with acetonitrile and tert-butyl alcohol mixed in $1: 1$ volume ratio.

Regarding the fabrication of the graphene/Pt counter electrode, APPJ was used to sinter the printed graphene $/ \mathrm{Pt}$ pastes for 5,9 , and $14 \mathrm{~s}$. The printed area was $1 \mathrm{~cm} \times 1 \mathrm{~cm}$.

The DSSC was assembled by sandwiching the $\mathrm{TiO}_{2}$ photoanode and the graphene/Pt counter electrode with a $25 \mu \mathrm{m}$ thick spacer. A commercial liquid electrolyte (E-Solar EL 100, Everlight Chemical Industrial Co., Taipei, Taiwan) consisting of $\mathrm{I}_{2}$, LiI, guanidinium thiocyanate (GuNCS), and acetonitrile was then injected into the assembled cells to complete the fabrication the DSSC.

\subsection{Characterization of DSSCs and Materials}

The DSSC was characterized using a solar simulator (Oriel Sol3A) equipped with an electrometer (Keithley 2400, Tektronix, Inc., Beaverton, AL, USA). The simulated light intensity is $100 \mathrm{~mW} / \mathrm{cm}^{2}$. The surface morphology was inspected using a scanning electron microscope (SEM, Nova NanoSEM 230, FEI, part of Thermo Fisher Scientific, Hillsboro, AL, USA). The water contact angle was measured using a goniometer (Model 100SB, Sindatek Instruments Co., Ltd., Taipei, Taiwan). Plasma emission spectra was recorded using a spectrometer (USB4000, Ocean Optics, Dunedin, FL, USA). 


\section{Results}

Figure 3 shows the representative emission spectrum evolution for the APPJ-sintering of the sample with an added $100 \mu \mathrm{L} \mathrm{H}_{2} \mathrm{PtCl}_{6}$ solution. The emissions at around 359, 388, 418, and $453 \mathrm{~nm}$ are attributed to the $\mathrm{CN}\left(\mathrm{CN}\right.$ violet system) violet system $\left(\mathrm{B}^{2} \Sigma \rightarrow \mathrm{X}^{2} \Sigma\right)$. This indicates a vigorous reaction between the nitrogen reactive species in the plasmas and the carbon-based materials. The $\mathrm{CN}$ emissions increased rapidly after the APPJ was ignited. Further increasing the APPJ sintering time reduced the intensity of $\mathrm{CN}$ emissions (some remained because the $\mathrm{N}_{2}$ 2nd positive emissions, partly overlapped with the $\mathrm{CN}$ emissions) owing to the decreasing amount of carbon-based materials (rGO, organic binders, and the organic solvent). The other remaining emissions were attributed to the persistent $\mathrm{N}_{2}$ 1st positive emissions at wavelengths longer than $530 \mathrm{~nm}$.

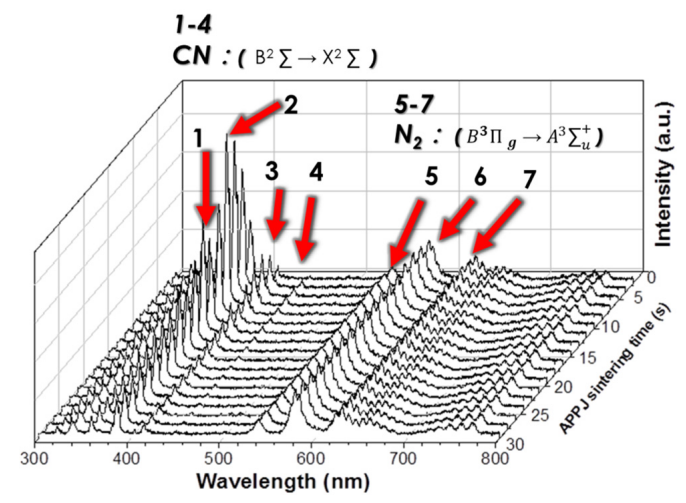

Figure 3. Plasma spectrum evolution during APPJ sintering on samples with added $100 \mu \mathrm{L}$ $\mathrm{H}_{2} \mathrm{PtCl}_{6}$ solution.

Figure 4 shows SEM images of $9 \mathrm{~s}$ APPJ-sintered bare rGOs (Figure 4a) and Pt-decorated rGOs (Figure $4 \mathrm{~b}$ ). After APPJ sintering, the rGOs become flake-like with some sharp edges. Figure 4c shows the magnified image indicated by the red square in Figure $4 \mathrm{~b}$. It can be clearly observed that some $\mathrm{Pt}$ dots are attached to the rGO flakes. The distribution of the Pt dots is pretty uniform and well-separated. No apparent agglomeration is observed. The energy dispersive spectrum (EDS) in Figure $4 \mathrm{~d}$ clearly indicates the presence of Pt on our samples. This suggests that our APPJ-sintering process can efficiently produce Pt-decorated rGOs.

Figure 5 shows the water contact angles of samples (with a $100 \mu \mathrm{L} \mathrm{H}_{2} \mathrm{PtCl}_{6}$ solution added) sintered by APPJ various times. Without APPJ sintering, the contact angle was as high as $142^{\circ}$; as the APPJ sintering time increased, the contact angle decreased. In our previous studies regarding APPJ-processed rGOs [24] and graphite felts [9], APPJ processing introduced surface groups containing $\mathrm{C}-\mathrm{O}$ and $\mathrm{C}=\mathrm{O}$ bonds on the surfaces of the carbon-based materials, leading to a decrease in the water contact angles [3]. This agrees with the present study. The formation of Pt nanoparticles on the rGO flakes may also enhance the wettability. The improved wettability facilitates the contact of the electrolyte and the $\mathrm{rGO} / \mathrm{Pt}$ counter electrodes; this also results in improved DSSC performance, as explained below.

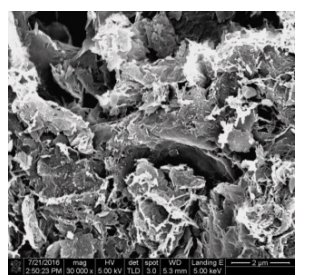

(a)

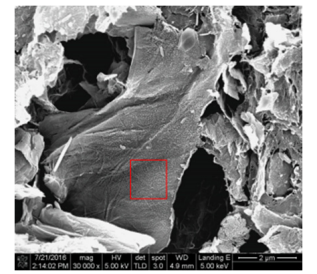

(b)

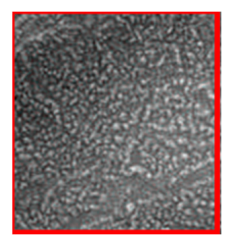

(c)

Figure 4. Cont. 

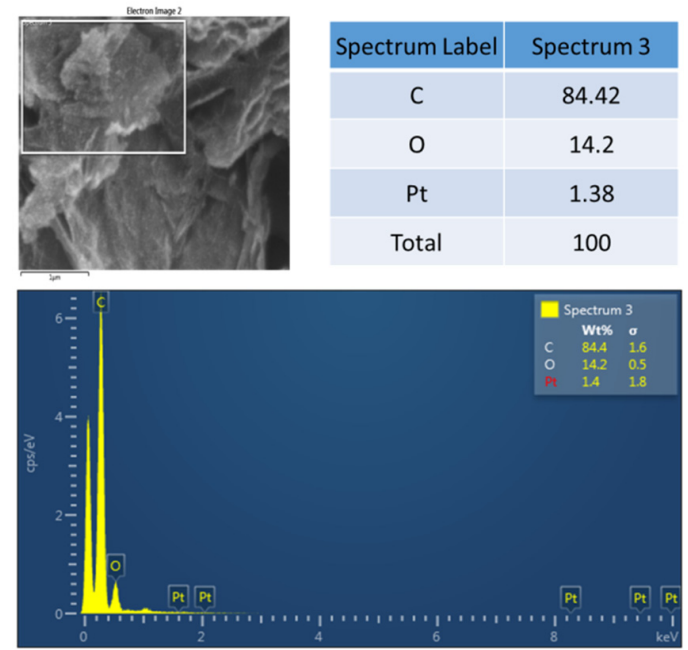

(d)

Figure 4. SEM images of $9 \mathrm{~s}$ APPJ-sintered (a) reduced graphene oxides (rGOs) (without adding $\mathrm{H}_{2} \mathrm{PtCl}_{6}$ solution in the pastes); (b) Pt-decorated rGOs (with $50 \mu \mathrm{L} \mathrm{H}_{2} \mathrm{PtCl}_{6}$ solution in the pastes); (c) Magnified image of the squared region shown in (b); (d) EDS spectrum.

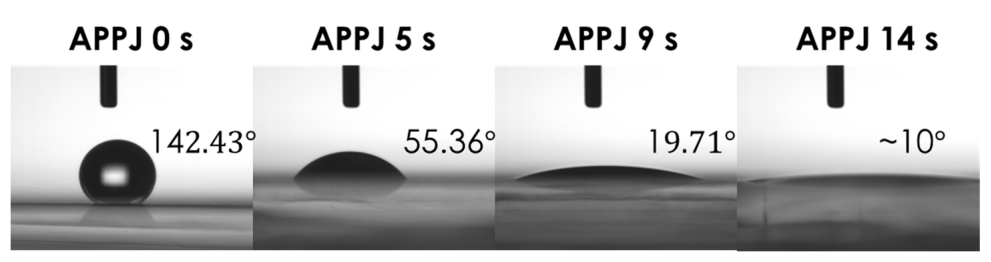

Figure 5. Water contact angles of samples (100 $\mu \mathrm{L} \mathrm{H}_{2} \mathrm{PtCl}_{6}$ solution added) sintered by APPJ for various times.

Figure 6 shows the representative IV (current density-voltage) curves. Figure 6a shows the IV curves of DSSCs fabricated using pastes with a $100 \mu \mathrm{L} \mathrm{H}_{2} \mathrm{PtCl}_{6}$ solution under various APPJ sintering times. It can be clearly observed that the DSSC performance is extremely poor without APPJ sintering owing to the presence of non-conducting organic binders (ethyl celluloses and terpineol) in the pastes. APPJ sintering can remove these binders and improve the contact between the electrolyte and the rGO/Pt counter-electrodes, resulting in better DSSC performance. The improved wettability of the APPJ-sintered $\mathrm{rGO} / \mathrm{Pt}$ counter-electrodes also facilitates contact between the electrolyte and the counter electrodes, thereby improving the cell performance. Furthermore, APPJ calcination reduced the chloroplatinic acid into Pt nanodots to enhance the catalytic effect; this also improved DSSC performance. Figure $6 \mathrm{~b}$ shows the IV curves of DSSCs fabricated with pastes containing various volumes of $\mathrm{H}_{2} \mathrm{PtCl}_{6}$ solutions (APPJ sintering time $=9 \mathrm{~s}$ ). The addition of $\mathrm{Pt}$ into the counter electrode can improve the fill factor (FF), thereby increasing cell efficiency.

DSSC parameters such as efficiency (EFF), fill factor $(\mathrm{FF})$, short circuit current density $\left(J_{\mathrm{sc}}\right)$, and open circuit voltage $\left(V_{\text {oc }}\right)$ can be determined from the IV curves. Tabulated DSSC parameters extracted from IV curves were shown in Table 1. Figure 7 shows a plot of these parameters against the APPJ treatment time. Without APPJ sintering, the cell performance was extremely poor. In all cases (compared under fixed $\mathrm{H}_{2} \mathrm{PtCl}_{6}$ volume), APPJ sintering improved the cell performance. The cell efficiency increased and then decreased as the APPJ sintering time increased. The best cell efficiency was achieved with $9 \mathrm{~s}$ APPJ sintering. As the amount of added $\mathrm{H}_{2} \mathrm{PtCl}_{6}$ solution increased, the cell performance improved, suggesting that Pt still exhibits a better catalytic effect. Regarding the addition of Pt into the counter-electrodes, the major improvement was in FF. The cell efficiency mostly improved 
owing to the improvement in FF. For $9 \mathrm{~s}$ APPJ sintering, the largest FF was achieved. Without any addition of Pt, there was a dramatic change in FF as the APPJ sintering time increased from 9 to $14 \mathrm{~s}$. By contrast, with Pt, FF was maintained at a similar level as APPJ sintering time increased from 9 to $14 \mathrm{~s}$. This is because Pt can sustain longer calcination via APPJ, whereas rGOs are largely removed when the APPJ sintering time is too long, leading to a decrease in FF and cell efficiency. The plot of $V_{\text {oc }}$ versus the APPJ treatment time shows that the APPJ sintering time has only a slight effect on $V_{\mathrm{oc}} . V_{\mathrm{oc}}$ increased slightly with the APPJ sintering time. In DSSC, $V_{\mathrm{oc}}$ is mainly determined by the quasi-Fermi level of the $\mathrm{TiO}_{2}$ and the redox potential of the electrolyte. This was not significantly altered by APPJ sintering. Therefore, $V_{\mathrm{oc}}$ remains at a similar level as APPJ sintering time increases. The APPJ sintering time also influenced $J_{\mathrm{sc}}$ slightly; $J_{\mathrm{sc}}$ increased and then decreased as the APPJ sintering time increased, reaching a maximum APPJ sintering time of $9 \mathrm{~s}$. Organic binders, ethyl cellulose and terpineol, may potentially obstruct the carrier transport. After APPJ sintering, the binders were removed to improve the contact between rGOs, thereby facilitating the carrier transport and increasing $J_{\mathrm{sc}}$. Over-calcination via APPJ, however, damages rGOs to reduce the catalytic effect and efficient carrier transport, leading to a decrease in $J_{\mathrm{sc}}$.

(a)

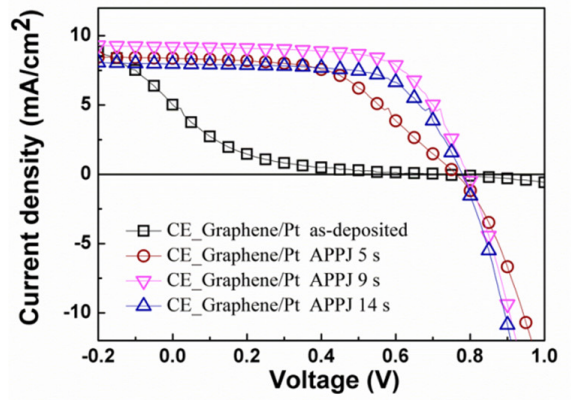

(b)

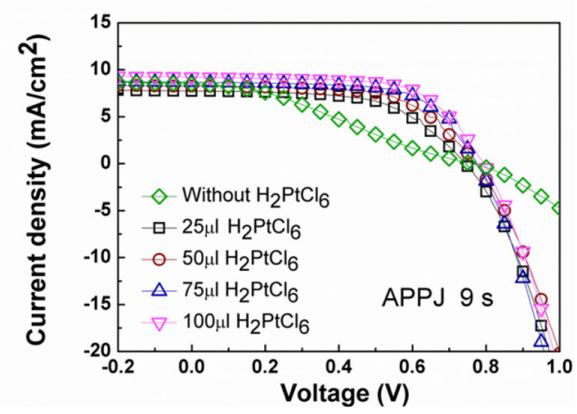

Figure 6. Representative IV (current density-voltage) curves. (a) Dye-sensitized solar cells (DSSCs) fabricated using pastes with a $100 \mu \mathrm{L} \mathrm{H}_{2} \mathrm{PtCl}_{6}$ solution under various APPJ sintering times; (b) DSSCs fabricated using pastes with various volumes of $\mathrm{H}_{2} \mathrm{PtCl}_{6}$ solutions under a $9 \mathrm{~s}$ APPJ sintering time.
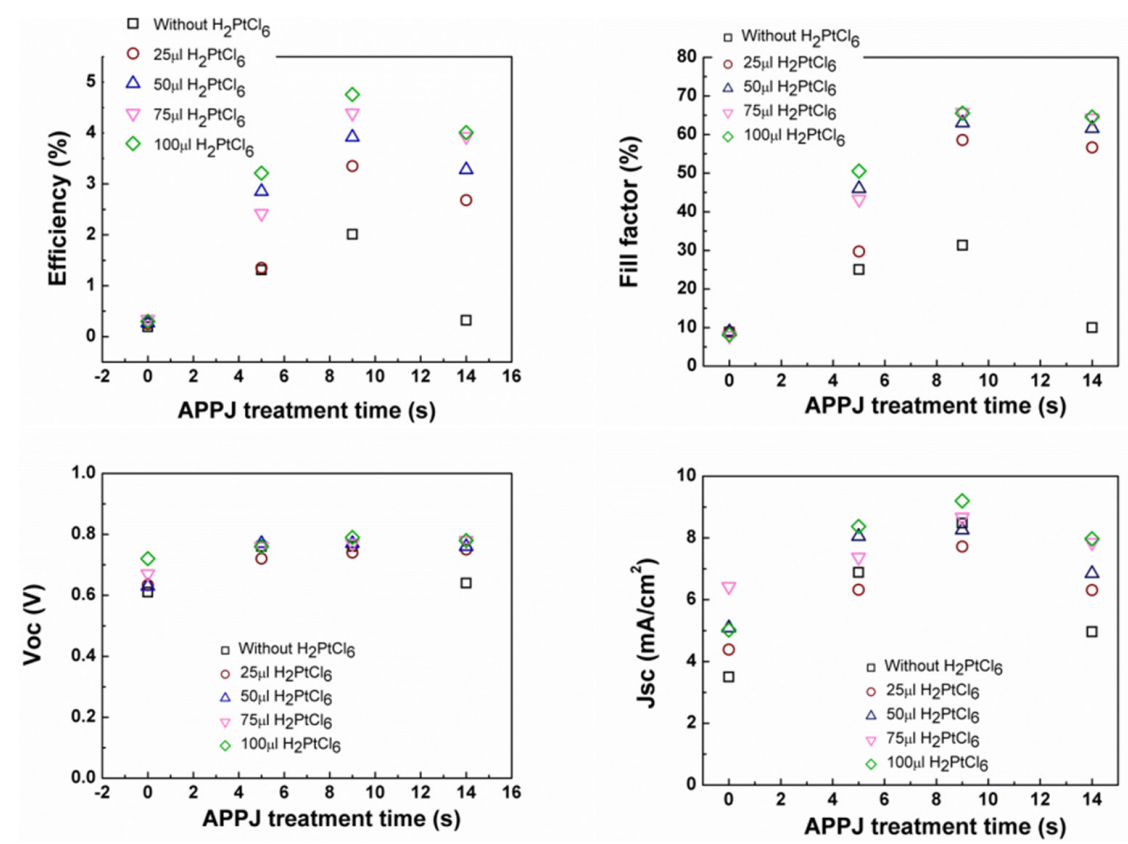

Figure 7. DSSC parameters (efficiency, fill factor (FF), open circuit voltage $\left(V_{\mathrm{oc}}\right)$, and short circuit current $\left(J_{\mathrm{sc}}\right)$ plotted against the APPJ treatment time. 
Table 1. Tabulated DSSC parameters extracted from IV curves. $0 \mu \mathrm{L}, 25 \mu \mathrm{L}, 50 \mu \mathrm{L}, 75 \mu \mathrm{L}, 100 \mu \mathrm{L}$ $\mathrm{H}_{2} \mathrm{PtCl}_{6}$ solution added in the pastes.

\begin{tabular}{|c|c|c|c|c|}
\hline APPJ Sintered & $0 \mathrm{~s}$ & $5 \mathrm{~s}$ & $9 \mathrm{~s}$ & $14 \mathrm{~s}$ \\
\hline \multicolumn{5}{|c|}{$0 \mu \mathrm{L} \mathrm{H}_{2} \mathrm{PtCl}_{6}$ solution } \\
\hline$J_{\mathrm{sc}}\left(\mathrm{mA} / \mathrm{cm}^{2}\right)$ & 3.50 & 6.88 & 8.48 & 4.96 \\
\hline$V_{\mathrm{oc}}(\mathrm{V})$ & 0.61 & 0.76 & 0.74 & 0.64 \\
\hline $\mathrm{FF}(\%)$ & 8.76 & 25.03 & 31.14 & 9.96 \\
\hline EFF (\%) & 0.19 & 1.31 & 2.01 & 0.32 \\
\hline \multicolumn{5}{|c|}{$25 \mu \mathrm{LH}_{2} \mathrm{PtCl}_{6}$ solution } \\
\hline$J_{\mathrm{sc}}\left(\mathrm{mA} / \mathrm{cm}^{2}\right)$ & 4.39 & 6.32 & 7.72 & 6.31 \\
\hline$V_{\mathrm{oc}}(\mathrm{V})$ & 0.63 & 0.72 & 0.74 & 0.75 \\
\hline FF $(\%)$ & 8.90 & 29.70 & 58.57 & 56.62 \\
\hline $\mathrm{EFF}(\%)$ & 0.25 & 1.35 & 3.35 & 2.68 \\
\hline \multicolumn{5}{|c|}{$50 \mu \mathrm{L} \mathrm{H}_{2} \mathrm{PtCl}_{6}$ solution } \\
\hline$J_{\mathrm{sc}}\left(\mathrm{mA} / \mathrm{cm}^{2}\right)$ & 5.09 & 8.05 & 8.26 & 6.85 \\
\hline$V_{\mathrm{oc}}(\mathrm{V})$ & 0.63 & 0.77 & 0.77 & 0.76 \\
\hline FF $(\%)$ & 8.89 & 45.98 & 63.02 & 61.58 \\
\hline EFF (\%) & 0.27 & 2.85 & 3.92 & 3.28 \\
\hline \multicolumn{5}{|c|}{$75 \mu \mathrm{L} \mathrm{H}_{2} \mathrm{PtCl}_{6}$ solution } \\
\hline$J_{\mathrm{sc}}\left(\mathrm{mA} / \mathrm{cm}^{2}\right)$ & 6.42 & 7.37 & 8.67 & 7.85 \\
\hline$V_{\mathrm{oc}}(\mathrm{V})$ & 0.67 & 0.76 & 0.77 & 0.78 \\
\hline FF (\%) & 7.91 & 43.18 & 65.73 & 64.25 \\
\hline EFF (\%) & 0.34 & 2.42 & 4.39 & 3.93 \\
\hline \multicolumn{5}{|c|}{$100 \mu \mathrm{L} \mathrm{H}_{2} \mathrm{PtCl}_{6}$ solution } \\
\hline$J_{\mathrm{sc}}\left(\mathrm{mA} / \mathrm{cm}^{2}\right)$ & 5.02 & 8.37 & 9.20 & 7.97 \\
\hline$V_{\mathrm{oc}}(\mathrm{V})$ & 0.72 & 0.76 & 0.79 & 0.78 \\
\hline $\mathrm{FF}(\%)$ & 8.20 & 50.53 & 65.54 & 64.52 \\
\hline EFF (\%) & 0.30 & 3.21 & 4.76 & 4.01 \\
\hline
\end{tabular}

\section{Conclusions}

We successfully used a nitrogen dc-pulse APPJ to fabricate Pt-decorated rGOs that were used as the counter-electrodes in DSSCs. APPJ processing enhances the wettability, thereby improving the contact between the electrolyte and the counter electrode; this in turn increases the cell efficiency. APPJ processing also results in the formation of Pt nanodots and the removal of ethyl cellulose and terpineol; the former improves the catalytic effect, the latter improves the contact between the conducting rGO flakes, and both improve the DSSC performance. The DSSC efficiency increases and then decreases as the APPJ processing time increases; the optimal APPJ processing time is $9 \mathrm{~s}$. The addition of Pt in the counter electrodes of DSSCs mainly improves the FF, in turn improving the DSSC performance.

Acknowledgments: The authors gratefully acknowledge the funding support from the Ministry of Science and Technology of Taiwan under grant no. MOST 105-2221-E-002-047-MY3. The clean room facility was supported by the Nano-Electro-Mechanical-Systems Research Center at National Taiwan University.

Author Contributions: Jian-Zhang Chen designed the research direction and wrote the paper. I-Chun Cheng and Cheng-Che Hsu assisted in instruction of the research. Ting-Hao Wan conducted most of the experiments. Yi-Fan Chiu helped the early-stage setup of the experiments. Chieh-Wen Chen helped the operation of SEM.

Conflicts of Interest: The authors declare no conflicts of interest.

\section{References}

1. Schutze, A.; Jeong, J.Y.; Babayan, S.E.; Park, J.; Selwyn, G.S.; Hicks, R.F. The atmospheric-pressure plasma jet: A review and comparison to other plasma sources. IEEE Trans. Plasma Sci. 1998, 26, 1685-1694. [CrossRef] 
2. Roth, J.R.; Nourgostar, S.; Bonds, T.A. The one atmosphere uniform glow discharge plasma (OAUGDP)-a platform technology for the 21st century. IEEE Trans. Plasma Sci. 2007, 35, 233-250. [CrossRef]

3. Chen, J.Z.; Hsu, C.C.; Wang, C.; Liao, W.Y.; Wu, C.H.; Wu, T.J.; Liu, H.W.; Chang, H.; Lien, S.T.; Li, H.C.; et al. Rapid atmospheric-pressure-plasma-jet processed porous materials for energy harvesting and storage devices. Coatings 2015, 5, 26-38. [CrossRef]

4. Babayan, S.; Jeong, J.; Schütze, A.; Tu, V.; Moravej, M.; Selwyn, G.; Hicks, R. Deposition of silicon dioxide films with a non-equilibrium atmospheric-pressure plasma jet. Plasma Sour. Sci. Technol. 2001, 10, 573-578. [CrossRef]

5. Foest, R.; Kindel, E.; Ohl, A.; Stieber, M.; Weltmann, K.-D. Non-thermal atmospheric pressure discharges for surface modification. Plasma Phy. Control. Fusion 2005, 47, B525-B536. [CrossRef]

6. Chen, J.Z.; Wang, C.; Hsu, C.C.; CHeng, I.C. Ultrafast synthesis of carbon-nanotube counter-electrodes for dye-sensitized solar cells using an atmospheric-pressure plasma jet. Carbon 2016, 98, 34-40. [CrossRef]

7. Wang, C.; Cheng, I.C.; Chen, J.Z. Ultrafast atmospheric-pressure-plasma-jet sintering of nanoporous $\mathrm{TiO}_{2}-\mathrm{SnO}_{2}$ composites with features defined by screen-printing. ECS J. Solid State Sci. Technol. 2015, 4, 3020-3025. [CrossRef]

8. Chang, H.; Hsu, C.M.; Kao, P.K.; Yang, Y.J.; Hsu, C.C.; Cheng, I.C.; Chen, J.Z. Dye-sensitized solar cells with nanoporous $\mathrm{TiO}_{2}$ photoanodes sintered by $\mathrm{N}_{2}$ and air atmospheric pressure plasma jets with/without air-quenching. J. Power Sources 2014, 251, 215-221. [CrossRef]

9. Chen, J.Z.; Liao, W.Y.; Hsieh, W.Y.; Hsu, C.C.; Chen, Y.S. All-vanadium redox flow batteries with graphite felt electrodes treated by atmospheric pressure plasma jets. J. Power Sources 2015, 274, 894-898. [CrossRef]

10. Chou, C.Y.; Chang, H.M.; Liu, H.W.; Yang, Y.J.; Hsu, C.C.; Cheng, I.C.; Chen, J.Z. Atmospheric-pressureplasma-jet processed nanoporous $\mathrm{TiO}_{2}$ photoanodes and pt counter-electrodes for dye-sensitized solar cells. RSC Adv. 2015, 5, 45662-45667. [CrossRef]

11. Barwe, B.; Riedel, F.; Cibulka, O.E.; Pelant, I.; Benedikt, J. Silicon nanoparticle formation depending on the discharge conditions of an atmospheric radio-frequency driven microplasma with argon/silane/hydrogen gases. J. Phys. D Appl. Phys. 2015, 48, 314001. [CrossRef]

12. Kaniyoor, A.; Jafri, R.I.; Arockiadoss, T.; Ramaprabhu, S. Nanostructured pt decorated graphene and multi walled carbon nanotube based room temperature hydrogen gas sensor. Nanoscale 2009, 1, 382-386. [CrossRef] [PubMed]

13. Novoselov, K.S.; Geim, A.K.; Morozov, S.V.; Jiang, D.; Zhang, Y.; Dubonos, S.V.; Grigorieva, I.V.; Firsov, A.A. Electric field effect in atomically thin carbon films. Science 2004, 306, 666-669. [CrossRef] [PubMed]

14. Elias, D.C.; Nair, R.R.; Mohiuddin, T.M.G.; Morozov, S.V.; Blake, P.; Halsall, M.P.; Ferrari, A.C.; Boukhvalov, D.W.; Katsnelson, M.I.; Geim, A.K.; et al. Control of graphene's properties by reversible hydrogenation: Evidence for graphane. Science 2009, 323, 610-613. [CrossRef] [PubMed]

15. Nair, R.R.; Ren, W.C.; Jalil, R.; Riaz, I.; Kravets, V.G.; Britnell, L.; Blake, P.; Schedin, F.; Mayorov, A.S.; Yuan, S.J.; et al. Fluorographene: A two-dimensional counterpart of teflon. Small 2010, 6, 2877-2884. [CrossRef] [PubMed]

16. Liu, J.; Durstock, M.; Dai, L.M. Graphene oxide derivatives as hole and electron-extraction layers for high-performance polymer solar cells. Energy Environ. Sci. 2014, 7, 1297-1306. [CrossRef]

17. Chartarrayawadee, W.; Moulton, S.E.; Li, D.; Too, C.O.; Wallace, G.G. Novel composite graphene/platinum electro-catalytic electrodes prepared by electrophoretic deposition from colloidal solutions. Electrochim. Acta 2012, 60, 213-223. [CrossRef]

18. Ramakrishnan, S.; Pradeep, K.R.; Raghul, A.; Senthilkumar, R.; Rangarajan, M.; Kothurkar, N.K. One-step synthesis of Pt-decorated graphene-carbon nanotubes for the electrochemical sensing of dopamine, uric acid and ascorbic acid. Anal. Methods 2015, 7, 779-786. [CrossRef]

19. Wang, J.W.; Rathi, S.; Singh, B.; Lee, I.; Joh, H.I.; Kim, G.H. Alternating current dielectrophoresis optimization of pt-decorated graphene oxide nanostructures for proficient hydrogen gas sensor. ACS Appl. Mater. Interterfaces 2015, 7, 13768-13775. [CrossRef] [PubMed]

20. Dao, V.D.; Hoa, N.T.Q.; Larina, L.L.; Lee, J.K.; Choi, H.S. Graphene-platinum nanohybrid as a robust and low-cost counter electrode for dye-sensitized solar cells. Nanoscale 2013, 5, 12237-12244. [CrossRef] [PubMed]

21. Elbohy, H.; Aboagye, A.; Sigdel, S.; Wang, Q.; Sayyad, M.H.; Zhang, L.F.; Qiao, Q.Q. Graphene-embedded carbon nanofibers decorated with pt nanoneedles for high efficiency dye-sensitized solar cells. J. Mater. Chem. A 2015, 3, 17721-17727. [CrossRef] 
22. Hoshi, H.; Tanaka, S.; Miyoshi, T. Pt-graphene electrodes for dye-sensitized solar cells. Mater. Sci. Eng. B 2014, 190, 47-51. [CrossRef]

23. Yeh, M.H.; Lin, L.Y.; Su, J.S.; Leu, Y.A.; Vittal, R.; Sun, C.L.; Ho, K.C. Nanocomposite graphene/Pt electrocatalyst as economical counter electrode for dye-sensitized solar cells. Chemelectrochem 2014, 1, 416-425. [CrossRef]

24. Liu, H.W.; Liang, S.P.; Wu, T.J.; Chang, H.; Kao, P.K.; Hsu, C.C.; Chen, J.Z.; Chou, P.T.; Cheng, I.C. Rapid atmospheric pressure plasma jet processed reduced graphene oxide counter electrodes for dye-sensitized solar cells. ACS Appl. Mater. Interfaces 2014, 6, 15105-15112. [CrossRef] [PubMed]

(c)

(C) 2016 by the authors; licensee MDPI, Basel, Switzerland. This article is an open access article distributed under the terms and conditions of the Creative Commons Attribution (CC-BY) license (http:/ / creativecommons.org/licenses/by/4.0/). 